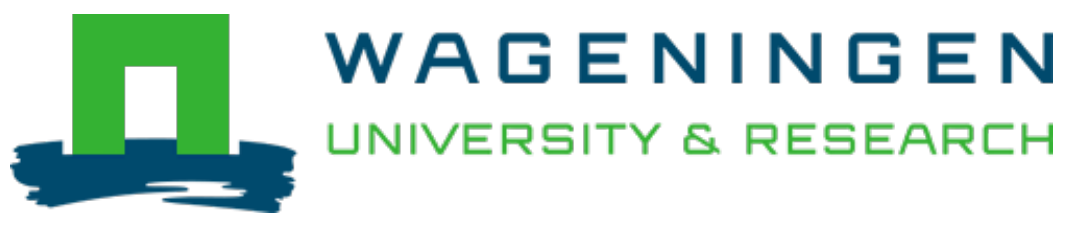

\author{
The effect of new bovine viral diarrhea virus introduction on somatic cell count, \\ calving interval, culling, and calf mortality of dairy herds in the Dutch bovine \\ viral diarrhea virus-free program \\ Journal of Dairy Science \\ Yue, Xiaomei; Voort, Mariska; Steeneveld, Wilma; Schaik, Gerdien; Vernooij, Johannes C.M. et al \\ https://doi.org/10.3168/jds.2021-20216
}

This article is made publicly available in the institutional repository of Wageningen University and Research, under the terms of article $25 \mathrm{fa}$ of the Dutch Copyright Act, also known as the Amendment Taverne. This has been done with explicit consent by the author.

Article $25 \mathrm{fa}$ states that the author of a short scientific work funded either wholly or partially by Dutch public funds is entitled to make that work publicly available for no consideration following a reasonable period of time after the work was first published, provided that clear reference is made to the source of the first publication of the work.

This publication is distributed under The Association of Universities in the Netherlands (VSNU) 'Article $25 \mathrm{fa}$ implementation' project. In this project research outputs of researchers employed by Dutch Universities that comply with the legal requirements of Article 25fa of the Dutch Copyright Act are distributed online and free of cost or other barriers in institutional repositories. Research outputs are distributed six months after their first online publication in the original published version and with proper attribution to the source of the original publication.

You are permitted to download and use the publication for personal purposes. All rights remain with the author(s) and / or copyright owner(s) of this work. Any use of the publication or parts of it other than authorised under article $25 \mathrm{fa}$ of the Dutch Copyright act is prohibited. Wageningen University \& Research and the author(s) of this publication shall not be held responsible or liable for any damages resulting from your (re)use of this publication.

For questions regarding the public availability of this article please contact openscience.library@wur.nl 


\title{
The effect of new bovine viral diarrhea virus introduction on somatic cell count, calving interval, culling, and calf mortality of dairy herds in the Dutch bovine viral diarrhea virus-free program
}

\author{
Xiaomei Yue, ${ }^{1 *}$ (ㄱ) Mariska van der Voort, ${ }^{1} \odot$ Wilma Steeneveld, ${ }^{2}$ () Gerdien van Schaik, ${ }^{2,3}$ () \\ Johannes C. M. Vernooij, ${ }^{2} \odot{ }^{\circ}$ Linda van Duijn, ${ }^{3} \odot$ and Henk Hogeveen ${ }^{1} \odot$ \\ ${ }^{1}$ Business Economics Group, Department of Social Sciences, Wageningen University, 6706 KN Wageningen, the Netherlands \\ ${ }^{2}$ Department of Population Health Sciences, Faculty of Veterinary Medicine, Utrecht University, 3584 CL Utrecht, the Netherlands \\ ${ }^{3}$ Royal GD, PO Box 9, 7400 AA Deventer, the Netherlands
}

\begin{abstract}
Bovine viral diarrhea virus (BVDV) infection has a major effect on the health of cows and consequently on herd performance. Many countries have implemented control or eradication programs to mitigate BVDV infection and its negative effects. These negative effects of BVDV infection on dairy herds are well documented, but there is much less information about the effects of new introduction of BVDV on dairy herds already participating in a BVDV control program. The objective of our study was to investigate the effect of a new BVDV introduction in BVDV-free herds participating in the Dutch BVDV-free program on herd performance. Longitudinal herd-level surveillance data were combined with herd information data to create 4 unique data sets, including a monthly test-day somatic cell count (SCC) data set, annual calving interval (CIV) and culling risk (CR) data sets, and a quarterly calf mortality rate (CMR) data set. Each database contained 2 types of herds: herds that remained BVDV free during the whole study period (defined as free herds), and herds that lost their BVDV-free status during the study period (defined as breakdown herds). The date of losing the BVDV-free status was defined as breakdown date. To compare breakdown herds with free herds, a random breakdown date was artificially generated for free herds by simple random sampling from the distribution of the breakdown month of the breakdown herds. The SCC and CIV before and after a new introduction of BVDV were compared through linear mixed-effects models with a Gaussian distribution, and the CR and CMR were modeled using a negative binomial distribution in generalized linear mixed-effects models. The explana-
\end{abstract}

Received January 26, 2021.

Accepted May 6, 2021.

*Corresponding author: xiaomei.yue@wur.nl tory variables for all models included herd type, BVDV status, year, and a random herd effect. Herd size was included as an explanatory variable in the SCC, CIV, and CMR model. Season was included as an explanatory variable in the SCC and CMR model. Results showed that free herds have lower SCC, CR, CMR, and shorter CIV than the breakdown herds. Within the breakdown herds, the new BVDV introduction affected the SCC and CMR. In the year after BVDV introduction, the SCC was higher than that in the year before BVDV introduction, with a factor of 1.011 [2.5th to 97.5th percentile (95\% PCTL): 1.002, 1.020]. Compared with the year before BVDV breakdown, the CMR in the year of breakdown and the year after breakdown was higher, with factors of 1.170 (95\% PCTL: 1.120; 1.218) and 1.096 (95\% PCTL: 1.048; 1.153), respectively. This study reveals that a new introduction of BVDV had a negative but on average relatively small effect on herd performance in herds participating in a BVDV control program.

Key words: bovine viral diarrhea virus, control program, somatic cell count, calving interval, culling

\section{INTRODUCTION}

Bovine viral diarrhea is endemic in many cattle-raising countries around the world (Houe, 1995; Pinior et al., 2019). The disease is caused by an infection with bovine viral diarrhea virus (BVDV), which results in diverse clinical manifestations, such as fever, reproductive dysfunctions, congenital defects, growth retardation, and death (Baker, 1995; Houe, 2003; Khodakaram-Tafti and Farjanikish, 2017). Through these manifestations, BVDV infection negatively affects the productivity and economic benefits of dairy herds (Richter et al., 2017).

It is well established that BVDV infection causes poor herd performance, resulting in decreased udder health, premature culling, extended calving intervals (CIV), and increased mortality among cows and calves 
Yue et al.: NEW BOVINE VIRAL DIARRHEA VIRUS INTRODUCTION

(Baker, 1995; Houe, 1995; Gunn et al., 2005; Richter et al., 2017). The bulk tank milk SCC in BVDV-infected herds is higher than in uninfected herds (Laureyns et al., 2013; Tschopp et al., 2017), ranging from 6,000 to 27,000 cells/mL (Lindberg and Emanuelson, 1997; Beaudeau et al., 2005; Laureyns et al., 2013). The CIV of the BVDV-infected herd was found to be 7 to $9 \mathrm{~d}$ longer than that of uninfected herds (Niskanen et al., 1995; Burgstaller et al., 2016), whereas a nonsignificant difference in the CIV between the BVDV-infected and uninfected herds was found (Berends et al., 2008; Tschopp et al., 2017). The time to first calving is 14 to $16 \mathrm{~d}$ longer in herds seroconverted to BVDV (Valle et al., 2001). Some studies show that the incidence of premature culling in clinical cases of BVDV infection is between $2 \%$ and 11\% (Pritchard et al., 1989; David et al., 1994; Bennett et al., 1999), whereas others find little evidence of an increased culling rate due to BVDV infection (Gates et al., 2013; Pinior et al., 2019). The calf mortality rate (CMR) in BVDV seropositive herds is 3 to 7 percentage points higher than that in negative herds (Ersbøll et al., 2003; Gates et al., 2013).

Many European countries and regions have implemented control or eradication programs to reduce the prevalence of BVDV and related direct losses (Lindberg et al., 2006; Santman-Berends et al., 2017; Evans et al., 2019; van Roon et al., 2020). In the Netherlands, a voluntary BVDV-free program was launched in 1997, and with success: the number of BVDV-free herds increased and the new BVDV circulation in these herds declined (van Duijn et al., 2019). The percentage of dairy herds with BVDV-free or BVDV-unsuspected status increased from $29 \%$ in 2011 to $65 \%$ in 2018 (GD Animal Health, 2011, 2018). The percentage of dairy herds with recent BVDV circulation dropped from $19.6 \%$ in $2009-2010$ to $8.7 \%$ in 2015-2016 (GD Animal Health, 2011, 2018). To further reduce BVDV infection and improve animal health and welfare in Dutch dairy herds, the compulsory national BVDV control program was formally introduced on April 1, 2018 (ZuivelNL, 2020). In the second quarter of $2020,81 \%$ of dairy herds had a BVDV-free or BVDV-unsuspected status (GD Animal Health, 2020).

Successful BVDV control programs are characterized by a low rate of new introductions of BVDV. The probability of new viral introduction in a herd after previous eradication is particularly important when determining the direct loss due to BVDV and assessing the efficiency of biosecurity measures in the BVDV control program (Lindberg et al., 2006; Stott et al., 2010). For herds participating in a BVDV control (or surveillance) program, it is possible to detect the BVDV circulation earlier, which may prevent further outbreaks and reduce the negative effects. However, the effect of new introduction of BVDV on herd performance (e.g., udder health, reproduction, culling, calf mortality) in a BVDV control program has not been quantified before.

The objective of our study was to investigate the effect of a new BVDV introduction on herd performance [i.e., SCC, CIV, culling risk (CR), and CMR] in BVDV-free herds participating in the Dutch BVDV-free program.

\section{MATERIALS AND METHODS}

\section{Data Collection}

Two data sets were collected to quantify the effect of new BVDV introduction on the SCC, CIV, CR, and CMR of dairy herds. The first data set consists of longitudinal herd-level BVDV status data and was previously described in Veldhuis et al. (2018) and Yue et al. (2021b). The BVDV status data set includes 4,334 dairy herds that participated in the Dutch BVDVfree program between September 4, 2006, and June 15, 2016. Figure 1 shows the 3 phases that make up the BVDV-free program procedure. Phase I is the test and cull phase. If no newborn calves test positive for BVDV for 10 consecutive months, the herd is certified as BVDV free and enters the monitoring phase (phase II). If BVDV is detected during phase II, the dairy herd loses its BVDV-free certificate and enters the removal phase for persistently infected (PI) animals (phase III). Two important dates in the BVDV-free program are the date on which a herd is certified as BVDV free (i.e., when the herd enters phase II), the so-called free date; and the date on which a herd loses its BVDV-free certificate (i.e., when the herd enters phase III), the socalled breakdown date. A herd that is certified BVDV free and stays in phase II until the end of the study period is defined as a free herd. A herd entering phase III is defined as a breakdown herd (Figure 1). The BVDV status data set also includes CMR records from January 1, 2011, to June 30, 2016 (i.e., the number of ear-tagged calves up to $1 \mathrm{yr}$ old that are reported dead in a quarter, divided by the number of calf-quarters at risk during that same time period; the calf-quarters at risk is calculated by taking the number of calves per mo, and then averaging that to a number per quarter).

The second data set includes herd information and was obtained from CRV (Cattle Improvement Cooperative, Arnhem, the Netherlands), including herd-level monthly or annual records of 20,796 Dutch dairy herds between January 1, 2007, and December 31, 2016. The monthly test-day records contain information on average cow SCC and the number of cows sampled for SCC on that test day. The annual records include the 
Yue et al.: NEW BOVINE VIRAL DIARRHEA VIRUS INTRODUCTION

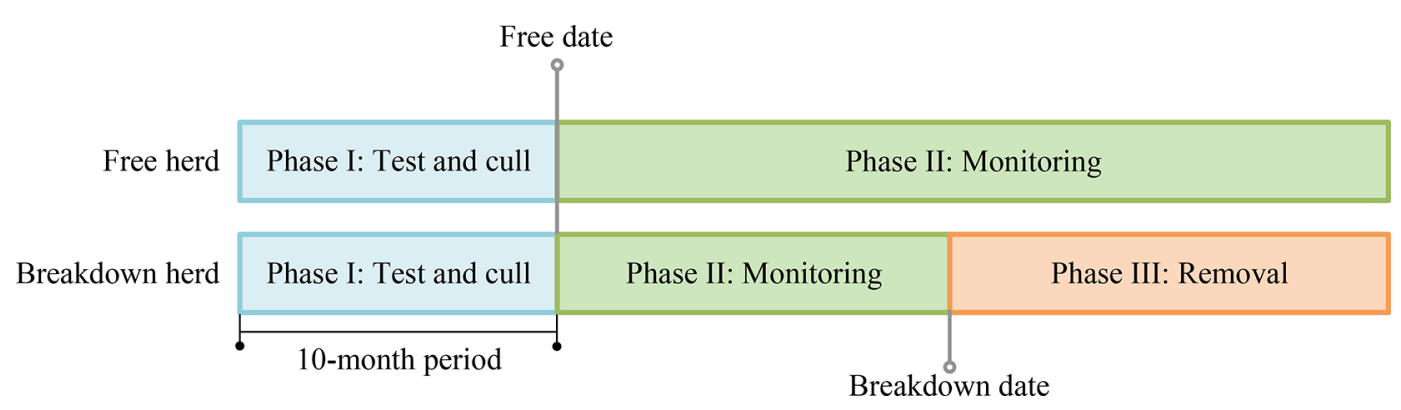

Figure 1. Three phases of the bovine viral diarrhea virus (BVDV)-free program in the Netherlands and the definition of free herds and breakdown herds. A breakdown herd lost its BVDV-free status during the study period, and a free herd remained BVDV free during the whole study period.

number of removed and present cows, the average CIV, and the number of cows used to calculate the average CIV. No animals were used in this study, so there is no experimental protocol that needs to be approved.

\section{Data Editing}

Four different data sets (for SCC, CIV, CR, and CMR) were created. The detailed data editing process of each data set is provided in Supplemental Figure S1 (https://doi.org/10.17026/dans-2zc-7w88, Yue et al., 2021a). For the SCC, CIV, and CR data sets, the herd information was merged with the BVDV status based on an anonymized unique herd number. The following herds were excluded: herds that quit the BVDV-free program before the end of the study period; herds with a breakdown date before January 1, 2008, or after December 31, 2014, to ensure sufficient date records before or after breakdown; herds with meaningless values (e.g., $\mathrm{SCC}=0, \mathrm{CIV}=0, \mathrm{CR}>1$, number of present cows $=0$, CMR $<0$ ) or records with missing data; and herds with $<20$ cows because they were not considered commercial farms. In addition, all records before the 10-mo period before the free date (phase I) were excluded to ensure that the studied herds are indeed free of BVDV before its defined new introduction. Records earlier than $2 \mathrm{yr}$ before and later than $3 \mathrm{yr}$ after the breakdown date were not used in the statistical analysis. The sample size was not calculated, and all herds that met the enrollment criteria were included in the study. The final 4 data sets include SCC data for 3,332 Dutch dairy herds, CIV data for 3,318 herds, CR data for 3,262 herds, and CMR data for 3,167 herds, from January 1, 2007, to December 31, 2016 (for CMR data set, from January 1, 2011, to June 30, 2016). The SCC data set comprises information on 234,367 monthly test days. The CIV and CR data set contain 23,231 and 23,431 annual records, respectively. The CMR data set consisted of 62,721 quarterly records.

\section{Statistical Analysis}

Descriptive statistics were performed on SCC, CIV, $\mathrm{CR}$, and CMR for both breakdown and free herds. To estimate the effect of BVDV breakdown on the herd performance on the breakdown herds, the herd performance was compared before and after breakdown. To correct for other effects in the outcome besides the change in BVDV status, such as weather, policy, and management decisions, free herds were also included in the analysis. Random breakdown dates were generated for free herds by simple random sampling from the distribution of the breakdown month of the breakdown herds. Consequently, the changes in herd performance due to BVDV breakdown could be calculated by comparing the differences in herd performance before and after the breakdown date on the breakdown herds, taking into account differences in herd performance before and after the artificial BVDV breakdown date of the free herds. Data editing and analysis were conducted in $\mathrm{R}$ version 3.5.0 (R Core Team, 2018).

Somatic Cell Count. The effect of BVDV breakdown on SCC was analyzed per year and per quarter. For the former, the $2 \mathrm{yr}$ before and $3 \mathrm{yr}$ after BVDV breakdown were taken into account. A linear mixedeffects model was applied as follows:

$$
\begin{aligned}
& \ln (S C C)_{i j}=\beta_{0}+\beta_{1} B H_{-} F_{i}+\beta_{2} B V D V \text { status }_{i j} \\
& +\beta_{3}\left(B B_{-} F_{i} \times B V D V \text { status }_{i j}\right)+\beta_{4} \text { No. of } \text { animals }_{i j} \\
& +\beta_{5} \text { Year }_{i j}+\beta_{6} \text { Season }_{i j}+\mu_{\text {herd }(i)}+\varepsilon_{i j} .
\end{aligned}
$$

For herd $i \in\{1, \ldots, 3,332\}$ and test-day $j \in\{01 / 01 / 2007, \ldots, 12 / 31 / 2016\}$, where $S C C_{i j}$ is the average SCC per cow on test day $j$ of herd $i$, in units of 1,000 cells $/ \mathrm{mL}$. Because of the right skewed distribution of the SCC value, it was natural log-transformed. 


\section{Yue et al.: NEW BOVINE VIRAL DIARRHEA VIRUS INTRODUCTION}

$B H \_F H_{i}$ is a dummy variable that represents herd type (breakdown herd or free herd). BVDV status $_{i j}$ is a defined categorical variable, which indicates the BVDV status of herd $i$ on test day $j$. BVDV status $i j$ was defined based on the BVDV breakdown date (real and artificial) and consists of 5 categories: 2 yr before breakdown, $1 \mathrm{yr}$ before breakdown, 1 yr after breakdown, 2 yr after breakdown, and 3 yr after breakdown. The 1 yr before breakdown category was used as the reference category. The effect of BVDV introduction on SCC within the breakdown herd can be explained by the coefficients of the interaction term $B H \_F H \times B V D V$ status in the model results. No. of animals $_{i j}$ is the number of cows sampled on the test day for SCC. Year ${ }_{i j}(2007-2016)$ is a categorical variable that corrects for variation in SCC across different calendar years, with 2007 as the reference year. Season $i j$ is a categorical variable defined as spring (March-May), summer (June-August, reference category), autumn (September-November), and winter (December to next February). In the Netherlands, dairy farms have a year-round calving pattern (Derks et al., 2013); thus, the effect of the time of BVDV introduction on the seasonal calving system was not considered. $\mu_{\text {herd }(i)}$ refers to the random herd effect in the ith herd that takes into account repeated measures within one herd (Dohoo et al., 2003). Further, the errors $\varepsilon_{1 j, \ldots,} \varepsilon_{3,332 j}$ are assumed to be independent with $\sim N\left(\mathbf{0}, \sigma^{2}\right)$, where $\sigma^{2}$ is the variance component. Maximum likelihood estimates of the parameters in the linear mixed model were determined using the lmer function in the lme4 package for $\mathrm{R}$ (Bates et al., 2015).

For the quarterly effect of BVDV breakdown on SCC, the model is similar, the only difference being the definition of the BVDV status variable. The quarterly analysis consisted of 5 categories representing the year before the BVDV breakdown date (reference category) and the first 4 quarters (quarter 1-quarter 4) of the year after BVDV breakdown.

The process of generating the random breakdown date and fitting the annual and quarterly SCC models was iterated 200 times, as were the models of the other studied parameters. Two hundred iterations were considered sufficient when the differences between the average transformed coefficients of the first 100 iterations and those of the last 100 iterations were less than 0.01 . To include the uncertainty of generating the random artificial breakdown date for the free herds, a random breakdown date for the free herds was generated within each iteration. In addition, each iteration included a data editing step before running the model to ensure that all studied herds have data on the year before and the year after BVDV breakdown. The modeling results for each of the 200 iterations were combined to provide a final outcome, which included the mean, standard deviation, and 2.5th to 97.5 th percentile (95\% PCTL) of the natural exponential transformed coefficients of the 200 iterations. As the artificial breakdown date generated for free herds in each iteration is random, the significance of the model results was indicated by the summary of coefficients of 200 iterations instead of the $P$-value of each iteration. This 95\% PCTL can inform the decision to (not) reject the hypothesis about a systematic increase or decrease of SCC or other herd performance variables. The normal distribution of the residuals of one iteration of the linear mixed model outcome was evaluated by visual inspection. The performance of the model was checked using the check_model function in $\mathrm{R}$ package performance (Lüdecke et al., 2019). The conditional $R^{2}$, which indicates how much the model variance is explained by both fixed and random factors (Nakagawa and Schielzeth, 2013), was also calculated with the performance package.

Calving Interval. As CIV data are available per year, the effect of a new BVDV introduction on CIV was analyzed per year as well. In line with the SCC model, a linear mixed-effects model was applied to the CIV analysis, and specific model composition and variable definitions are shown in Table 1. The model-fitting procedure was the same as the SCC model. The modeling results were summarized with the mean, standard deviation, minimum, maximum, and 95\% PCTL of the natural exponential transformed coefficients of the 200 iterations.

Culling Risk. Culling risk is available per year, so the effect of new introduction of BVDV on CR was analyzed per year. The herd-level CR was estimated using negative binomial distribution, and a logit-link function was used in a generalized linear mixed-effects model:

$$
\begin{aligned}
& \text { Culling Risk }_{i k}=\beta_{0}+\beta_{1} B H_{-} F_{i}+\beta_{2} B V D V \text { status }_{i k} \\
& +\beta_{3}\left(B B_{-} F_{i} \times B V D V \text { status }_{i k}\right)+\beta_{4} \text { Year }_{i k}+\mathbf{Z} u_{i k} .
\end{aligned}
$$

For herd $i \in\{1, \ldots, 3,262\}$ and year $k \in\{2007, \ldots, 2016\}$, where Culling Risk ik $_{\text {was }}$ calculated by dividing the number of removed cows by the number of present cows on year $k$ of herd $i$. The definition of explanatory variables $B H_{-} F H_{i}, B V D V$ status $_{i k}$, and $Y_{e a r}$ ik shown in Table 1. The random herd effect is $u_{i k}$ and $\mathbf{Z}$ is the design matrix for the random part of the model (Dohoo et al., 2003). The random herd effect was assumed to be normally distributed. Maximum likelihood estimates of the parameters in the generalized linear mixed model were determined using the glmmTMB function in the glmmTMB package for R (Magnusson et al., 2017). 
Yue et al.: NEW BOVINE VIRAL DIARRHEA VIRUS INTRODUCTION

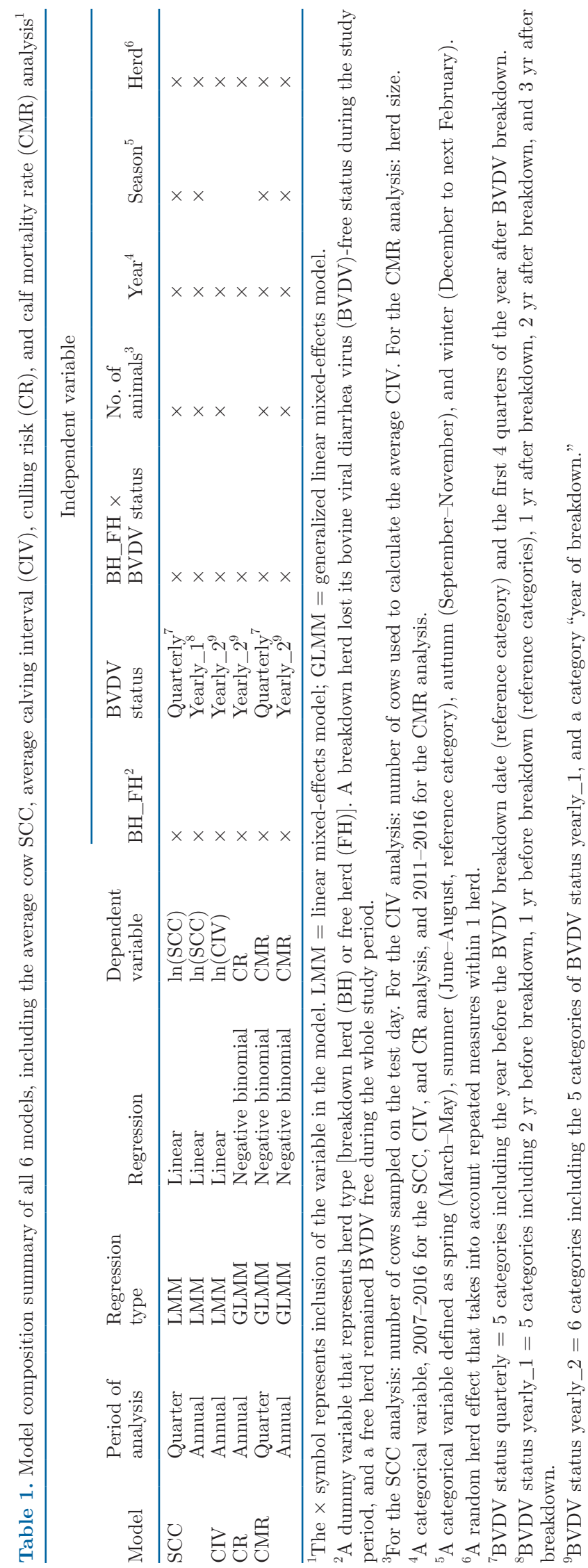

The model-fitting procedure was the same as for the SCC model. Overdispersion of the model was checked using the testDispersion function in the DHARMa package (Hartig and Hartig, 2017). The theoretical conditional $\mathrm{R}^{2}$ that can be used for the binomial distribution was calculated with the r.squaredGLMM function in package MuMIn (Barton and Barton, 2019). The intercept term was transformed back to the probability, and the modeling results of fixed variables were summarized in the same way as for the CIV model.

Calf Mortality Rate. The CMR data were recorded quarterly; thus, the effect of a new BVDV introduction on CMR was analyzed per year and per quarter. A generalized linear mixed-effects model was applied (Table 1). The calf mortality data were fitted to a negative binomial distribution. The modeling results were summarized in the same way as for the CR model.

Subanalysis. Although all studied herds participated in the BVDV-free program, the antibody prevalence within each herd will vary, depending on when BVDV last circulated. The initial antibody prevalence can moderate the effect of BVDV introduction on herd performance. Therefore, a subanalysis was performed to determine the effect of initial BVDV antibody prevalence on the effects of BVDV introduction. The length of BVDV-free time (defined as the number of days between the free date and breakdown date) was used as an indicator of the BVDV antibody prevalence. The longer a herd is BVDV free, the lower the BVDV antibody prevalence within the herd is. Therefore, in the subanalysis, only herds that had a BVDV-free status for more than $3 \mathrm{yr}$ were included. After $3 \mathrm{yr}$ of BVDVfree status, the antibody prevalence in the herd was considered to be reduced to a low level (approximately $28 \%$, according to the control experience of infectious bovine rhinotracheitis in the Netherlands; Vonk Noordegraaf et al., 1998). The subanalysis was carried out for all 6 models mentioned in Table 1 .

\section{RESULTS}

\section{Descriptive Results}

Table 2 presents descriptive results of the herd performance (SCC, CIV, CR, and CMR) in relation to the BVDV status. The descriptive results show that the herd performance of free herds was generally better than of breakdown herds. The overall average SCC for breakdown herds and free herds was 198,000 cells/mL $(\mathrm{SD} \pm 87,000)$ and 187,000 cells $/ \mathrm{mL}(\mathrm{SD} \pm 87,000)$, respectively. The overall average CIV of cows in breakdown herds was on average $3 \mathrm{~d}$ longer than in free herds. The overall average CR in breakdown herds was $23.5 \%$ $(\mathrm{SD} \pm 8.4 \%)$, which was 0.3 percentage points higher 
Yue et al.: NEW BOVINE VIRAL DIARRHEA VIRUS INTRODUCTION

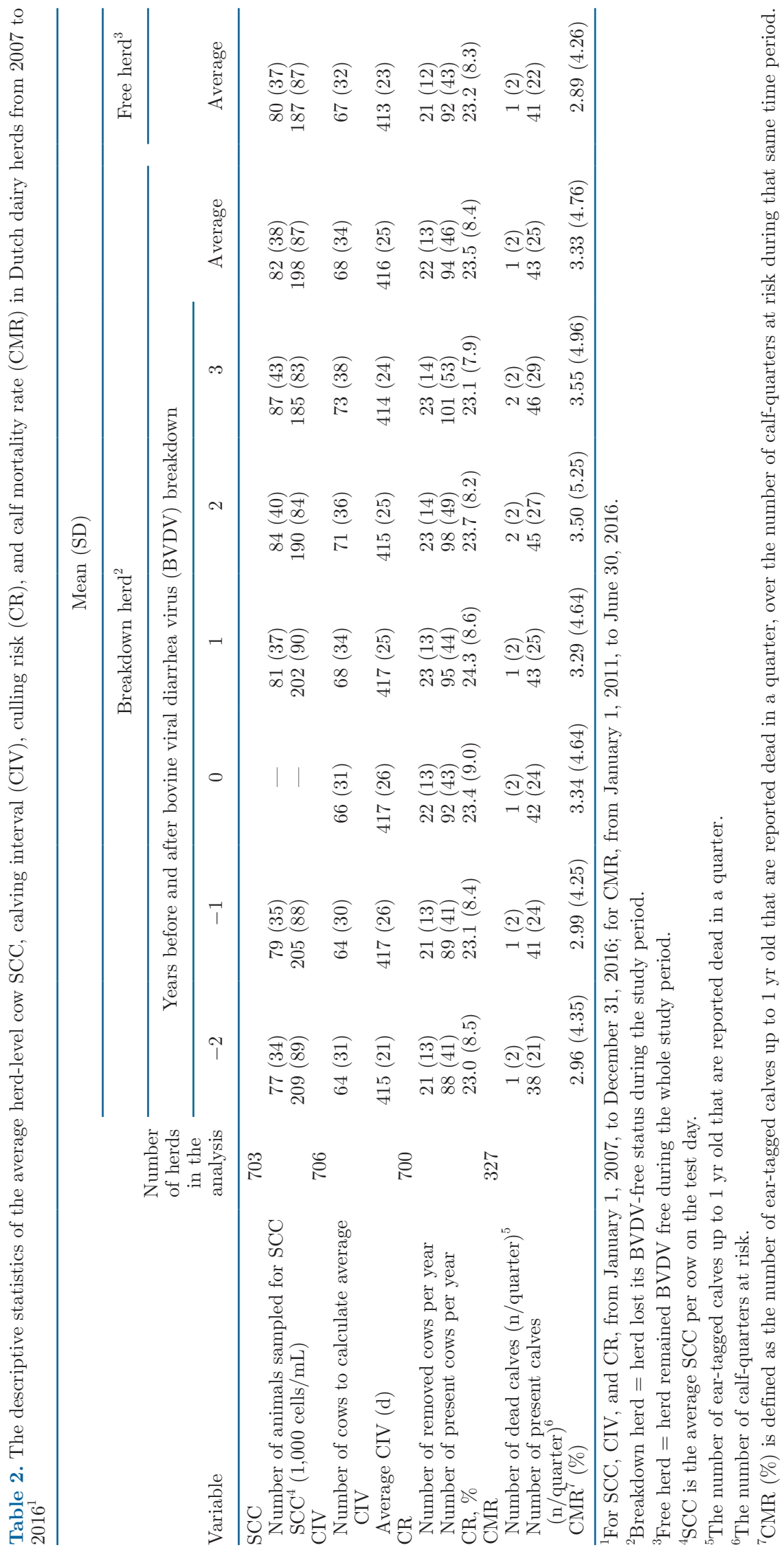




\section{Yue et al.: NEW BOVINE VIRAL DIARRHEA VIRUS INTRODUCTION}

than in free herds. The average CMR in breakdown herds was 0.44 percentage points higher than that in free herds. In addition, within the breakdown herds, SCC, CIV, CR, and CMR differed by years before or after BVDV breakdown.

\section{Somatic Cell Count}

Table 3 shows the summarized results of the SCC analysis. Figure 2a compares SCC in relation to BVDV breakdown in breakdown herds and free herds. Figure 3 a presents the results of the quarterly analysis. In the annual analysis, the SCC for breakdown herds was 1.008 (95\% PCTL: 1.000; 1.017) times higher than in free herds. The interaction term BH_FH $\times$ BVDV status indicated the effect of BVDV introduction on SCC within the breakdown herds. In the year after BVDV breakdown, the SCC was 1.011 (95\% PCTL: 1.002; 1.020) times higher than in the year before BVDV breakdown. The SCC decreased by a factor of 0.997

Table 3. Summarized natural exponentiated regression coefficients of the linear mixed-effects model with 200 iterations for the effects of bovine viral diarrhea virus (BVDV) breakdown on SCC $(1,000$ cells $/ \mathrm{mL})$ per cow in 703 breakdown herds ${ }^{1}$ and 2,629 free herds ${ }^{1}$ in the Netherlands

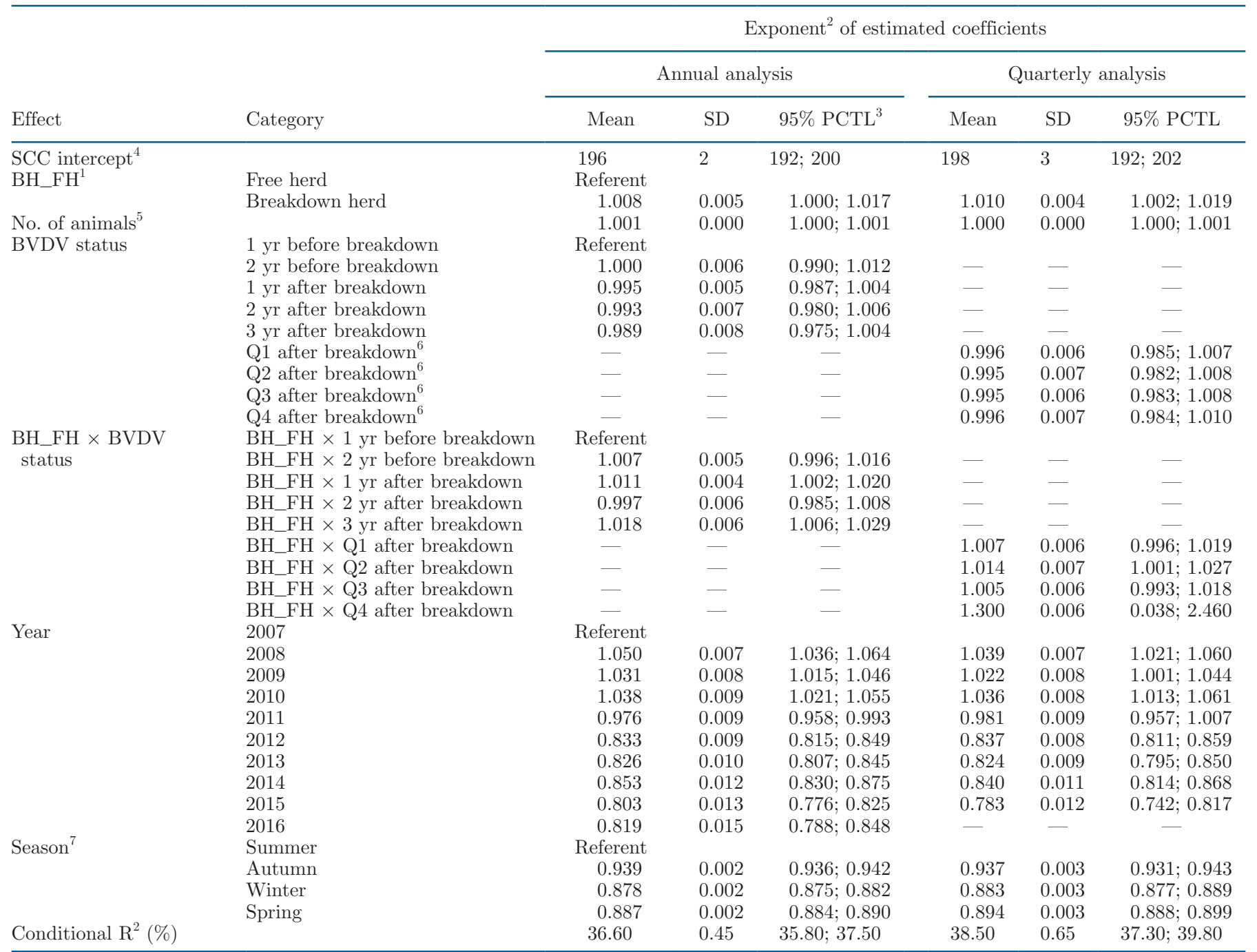

${ }^{1} \mathrm{~A}$ dummy variable indicating herd status [breakdown herd $(\mathrm{BH})$ or free herd $\left.(\mathrm{FH})\right]$. A breakdown herd lost its BVDV-free status during the study period; a free herd remained BVDV free during the whole study period.

${ }^{2}$ The natural exponentiated regression coefficient (except for the intercept term) is the ratio between the mean level of a specific category and the mean level of the reference category.

${ }^{3} 2.5$ th percentile to 97.5 th percentile of the parameter estimate.

${ }^{4}$ The geometric mean of SCC.

${ }^{5}$ Number of cows sampled on the test day for SCC.

${ }^{6} \mathrm{Q} 1, \mathrm{Q} 2, \mathrm{Q} 3$, and Q4 = the first, second, third, and fourth quarter following the BVDV breakdown date.

${ }^{7}$ Spring (March-May), summer (June-August), autumn (September-November), and winter (December to next February). 


\section{Yue et al.: NEW BOVINE VIRAL DIARRHEA VIRUS INTRODUCTION}

(95\% PCTL: $0.985 ; 1.008)$ in the second year after BVDV breakdown. In the quarterly analysis, the SCC increased mainly in the second quarter after BVDV breakdown, with a factor of 1.014 (95\% PCTL: 1.001; 1.027). Both the annual and quarterly analysis indicated that BVDV introduction has negative effects on $\mathrm{SCC}$ in breakdown herds.

\section{Calving Interval}

Table 4 shows the summarized modeling results for the CIV analysis. Figure $2 \mathrm{~b}$ compares the CIV in relation to the BVDV breakdown in breakdown herds and free herds. The CIV in breakdown herds was 1.005 (95\% PCTL: $1.003 ; 1.007)$ times higher than in free herds. Within the breakdown herds, there was no significant change in the average CIV, whether in the year of the breakdown (mean ratio 1.000, 95\% PCTL: 0.998; 1.002) or in the first $2 \mathrm{yr}$ after BVDV breakdown.

\section{Culling Risk}

Table 5 shows the modeling results for the CR analysis. Figure 2c compares the CR in relation to BVDV breakdown in breakdown and free herds. The mean intercept of CR was $20.4 \%$, and the CR in breakdown herds was on average 1.020 (95\% PCTL: 1.001; 1.040) times higher than in free herds. For the breakdown herds, the CR in the year of breakdown was lower than in the year before BVDV breakdown, with a factor of 0.972 (95\% PCTL: 0.949; 0.996). There was no significant effect of BVDV introduction on $\mathrm{CR}$ in the $2 \mathrm{yr}$ after breakdown.

\section{Calf Mortality Rate}

Table 6 shows the annual and quarterly modeling results for the CMR analysis. Figure 2d compares the CMR in relation to BVDV breakdown in breakdown and free herds. Figure $3 \mathrm{~b}$ presents the results of the quarterly analysis. The mean intercept of CMR in annual and quarterly results was $1.34 \%$ and $1.30 \%$, respectively, and the CMR in the breakdown herds was on average 1.105 (95\% PCTL: 1.062; 1.150) and 1.265 (95\% PCTL: $1.231 ; 1.292)$ times higher than in free herds, respectively. For the annual analysis results, the CMR in the year of the breakdown and the year after BVDV breakdown was 1.170 (95\% PCTL: 1.120; 1.218) and 1.096 (95\% PCTL: 1.048; 1.153) times higher than the year before BVDV breakdown, respectively. In the quarterly modeling results, the CMR increased in the first and third quarter after BVDV breakdown, which

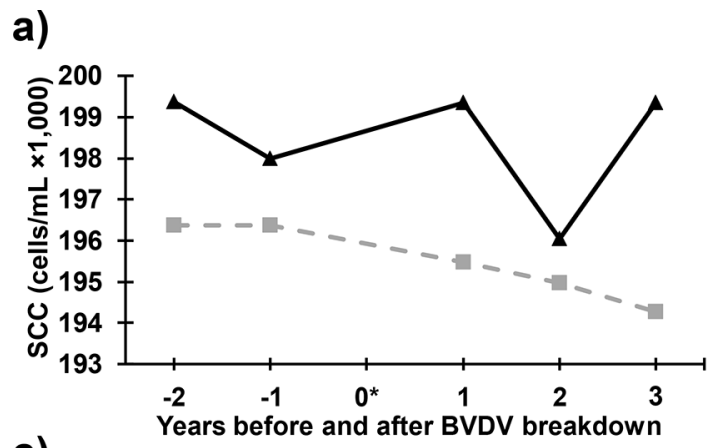

c)

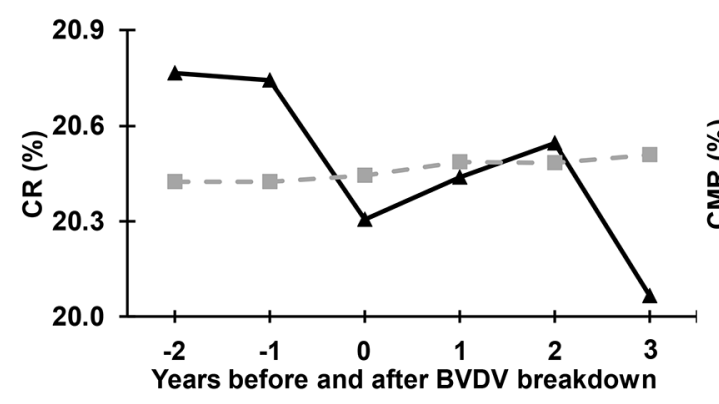

b)
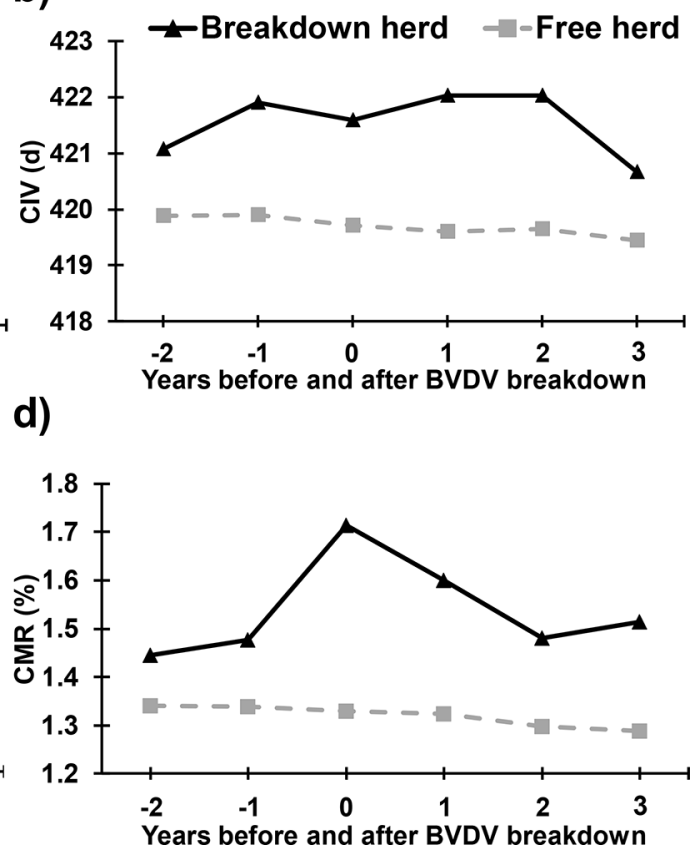

Figure 2. Effect of new introduction of bovine viral diarrhea virus (BVDV) on average cow SCC (a), calving interval (CIV; b), culling risk

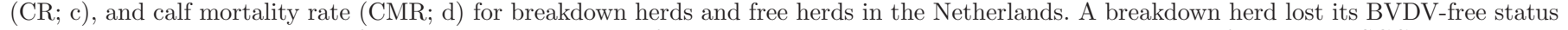

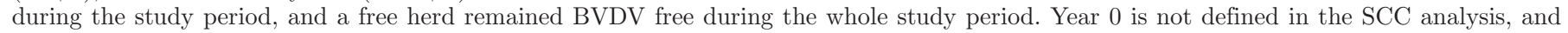

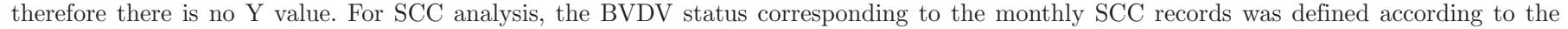

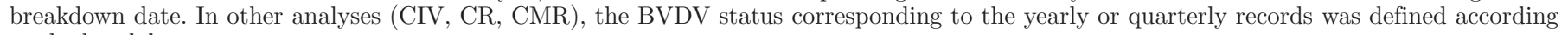
to the breakdown year. 
Yue et al.: NEW BOVINE VIRAL DIARRHEA VIRUS INTRODUCTION

was on average 1.070 (95\% PCTL: $1.009 ; 1.134)$ and 1.108 (95\% PCTL: 1.048; 1.179) times higher than the CMR in the year before BVDV breakdown, respectively. In the second and fourth quarter, the CMR was on average 0.941 (95\% PCTL: 0.890; 0.991) and 0.824 (95\% PCTL: 0.768 ; 0.889) times lower than the CMR in the year before BVDV breakdown, respectively. Both the annual and quarterly analysis indicate that BVDV introduction has a negative effect on CMR in breakdown herds.

\section{Subanalysis}

The subanalysis comprised herds that were BVDV free for more than $3 \mathrm{yr}$. The descriptive results and estimates of the subanalysis for all 6 models are listed in Supplemental Tables S1, S2, and S3 (https://doi .org/10.17026/dans-2zc-7w88, Yue et al., 2021a). For the subanalysis of SCC, the SCC in breakdown herds in the first, second, and third year after BVDV breakdown was 1.021 (95\% PCTL: 1.010; 1.032), 1.013 (95\% PCTL: $1.002 ; 1.023)$, and 1.042 (95\% PCTL: 1.033;
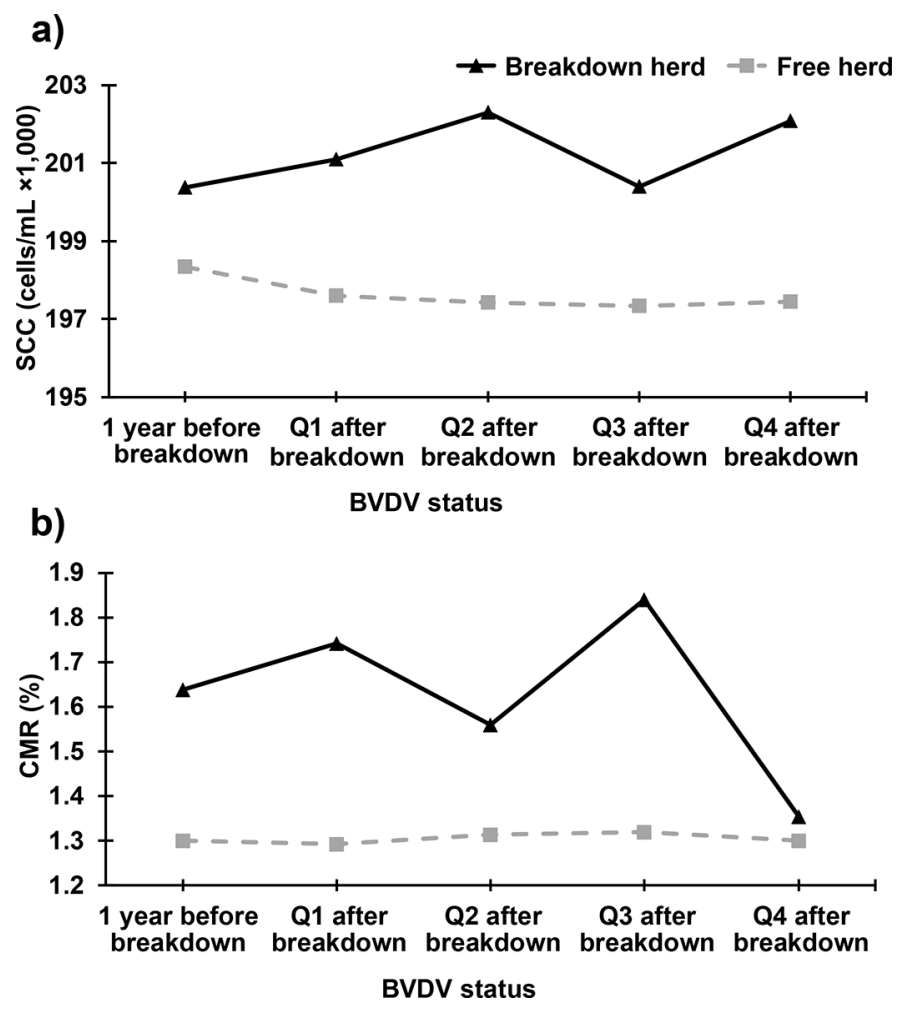

Figure 3. Effect of new introduction of bovine viral diarrhea virus (BVDV) on average cow SCC (a) and calf mortality rate (CMR; b) for breakdown herds and free herds in the first year after breakdown in the Netherlands. A breakdown herd lost its BVDV-free status during the study period, and a free herd remained BVDV free during the whole study period. Q1 = first quarter; Q2 = second quarter; Q3 = third quarter; $\mathrm{Q} 4$ = fourth quarter.
1.053) times higher than in the year before BVDV breakdown, respectively. The results show that, compared with the SCC for all studied herds, the SCC in herds that had the BVDV-free status for more than $3 \mathrm{yr}$ increased more after BVDV introduction. The average CIV of breakdown herds in the first and second year after breakdown was 1.005 (95\% PCTL: 1.003; 1.007) and 1.003 (95\% PCTL: $1.001 ; 1.005)$ times the average CIV in the year before BVDV breakdown in the subanalysis, respectively. Compared with the effect of BVDV introduction on the average CIV of all studied herds, BVDV introduction had a larger effect on the average CIV in herds that had a longer BVDV-free status. The subanalysis of the CR model showed that after BVDV introduction the reduction in $\mathrm{CR}$ was higher than in the overall analysis. In the year of breakdown, the CR in breakdown herds was 0.941 (95\% PCTL: $0.922 ; 0.961$ ) times lower than in the year before breakdown. The CMR of breakdown herds increased with a factor of 1.223 (95\% PCTL: 1.158; 1.280) and 1.156 (95\% PCTL: $1.094 ; 1.224)$ in the year of breakdown and the year after breakdown, respectively, compared with the CMR in the year before BVDV breakdown. Similar to the other parameters (i.e., SCC, CIV), the estimated negative effects of BVDV introduction on CMR increased for herds which were BVDV free for a longer time period.

\section{DISCUSSION}

The effect of a new BVDV introduction on herd performance was quantified by examining SCC, CIV, CR, and CMR in Dutch dairy herds participating in the BVDV-free program. This study combined the herdlevel BVDV surveillance data and herd performance information from January 1, 2007, to December 31, 2016. Both descriptive and multivariable model results show that BVDV-free herds perform better than breakdown herds. Free herds had lower SCC, CR, CMR, and shorter CIV. For the breakdown herds, our results indicate that a new BVDV introduction has a negative, but on average relatively small, effect on herd performance (mainly on SCC and CMR) in dairy herds participating in the BVDV control program.

The effect of BVDV infection on SCC is smaller in our study than in other studies. Beaudeau et al. (2005) and Laureyns et al. (2013) reported that the SCC in BVDV-infected herds was 6,000 to 31,400 cells $/ \mathrm{mL}$ higher than in noninfected herds. A possible explanation for the smaller effect of BVDV infection in our findings might be that all the studied herds in our study participated in the BVDV-free program. The studied herds were able to detect BVDV infection at an early stage. Moreover, in the BVDV-free program, 
Yue et al.: NEW BOVINE VIRAL DIARRHEA VIRUS INTRODUCTION

Table 4. Summarized exponentiated regression coefficients of the linear mixed-effects model with 200 iterations for the annual effect of bovine viral diarrhea virus (BVDV) breakdown on average calving interval (CIV; d) per cow in 706 breakdown herds ${ }^{1}$ and 2,612 free herds $^{1}$ in the Netherlands

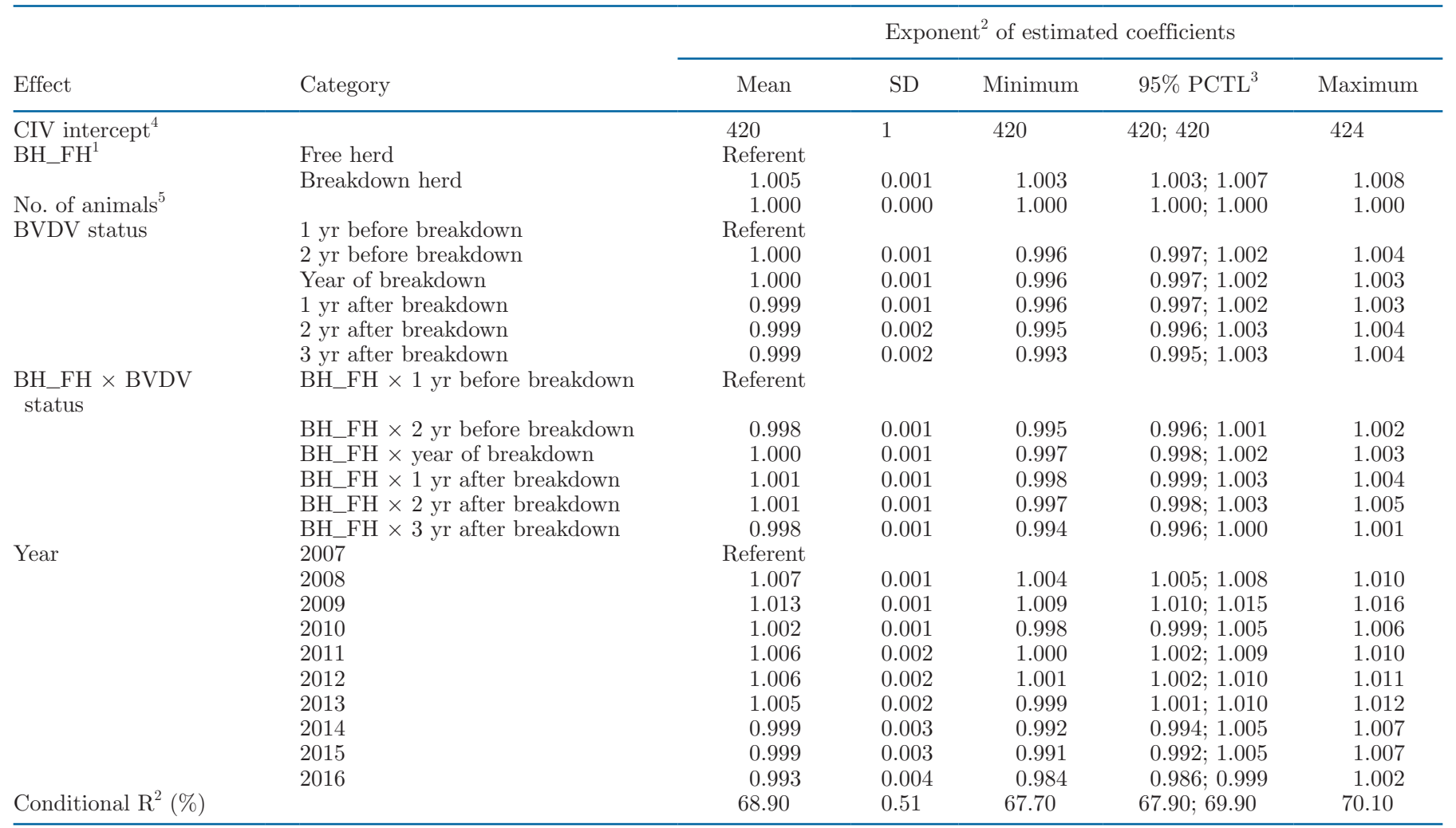

${ }^{1} \mathrm{~A}$ dummy variable indicating herd status [breakdown herd $(\mathrm{BH})$ or free herd $\left.(\mathrm{FH})\right]$. A breakdown herd lost its BVDV-free status during the study period, and a free herd remained BVDV free during the whole study period.

${ }^{2}$ The natural exponentiated regression coefficient (except for the intercept term) is the ratio between the mean level of a specific category and the mean level of the reference category.

${ }^{3} 2.5$ th percentile to 97.5 th percentile of the parameter estimate.

${ }^{4}$ The geometric mean of average CIV.

${ }^{5}$ Number of cows used to calculate the average CIV.

they were obligated to detect and cull the PI animals, so as to prevent more susceptible animals from being infected (and subsequent increase in cow SCC). These activities most probably will lead to relatively small effects of BVDV infections on herd performance. Another possible explanation for the smaller effect in our results is that previous studies were mostly cross-sectional studies and evaluated the effect of BVDV infection by comparing SCC in herds with different BVDV status. Few studies have investigated changes in SCC within BVDV-infected herds. Tschopp et al. (2017) assessed the effect of BVDV eradication on bulk milk SCC in Swiss dairy farms by matching case herds with more than one PI animal with control herds free of BVDV. After the eradication of BVDV, bulk milk SCC in case herds showed a slight decrease (Tschopp et al., 2017). However, other studies did not find a significant association between bulk milk SCC and BVDV status of the herd (Waage et al., 1994; Heuer et al., 2007; Rola et al., 2014; Shafaei Novdeh et al., 2020). The effect of BVDV introduction on SCC in our study mainly appeared in the first year after introduction, and this is in accordance with the findings of Beaudeau et al. (2005) and Laureyns et al. (2013).

Another finding is that CMR in breakdown herds increased significantly after a new BVDV introduction. These results are in accordance with previous studies indicating that BVDV infection attributes to mortality in young stock (Houe and Meyling, 1991; Bennett et al., 1999; Diéguez et al., 2009; Graham et al., 2013). However, the effect of BVDV infection on CMR found in our study is smaller than previous studies. Ersbøll et al. (2003) and Gates et al. (2013) reported that the CMR in herds affected with BVDV was 3.05 to 7.3 percentage points (calculated to be 1.47 to 2 times) higher than in herds free from BVDV. One possible reason for the difference in results is the fact that herds in our study can detect virus circulation and cull PI 
Yue et al.: NEW BOVINE VIRAL DIARRHEA VIRUS INTRODUCTION

Table 5. Summarized exponentiated regression coefficients of the generalized linear mixed-effects model (with logit-link function and negative binomial distribution) with 200 iterations for the annual effect of bovine viral diarrhea virus (BVDV) breakdown on culling risk (CR; \%) in 700 breakdown herds ${ }^{1}$ and 2,562 free herds ${ }^{1}$ in the Netherlands

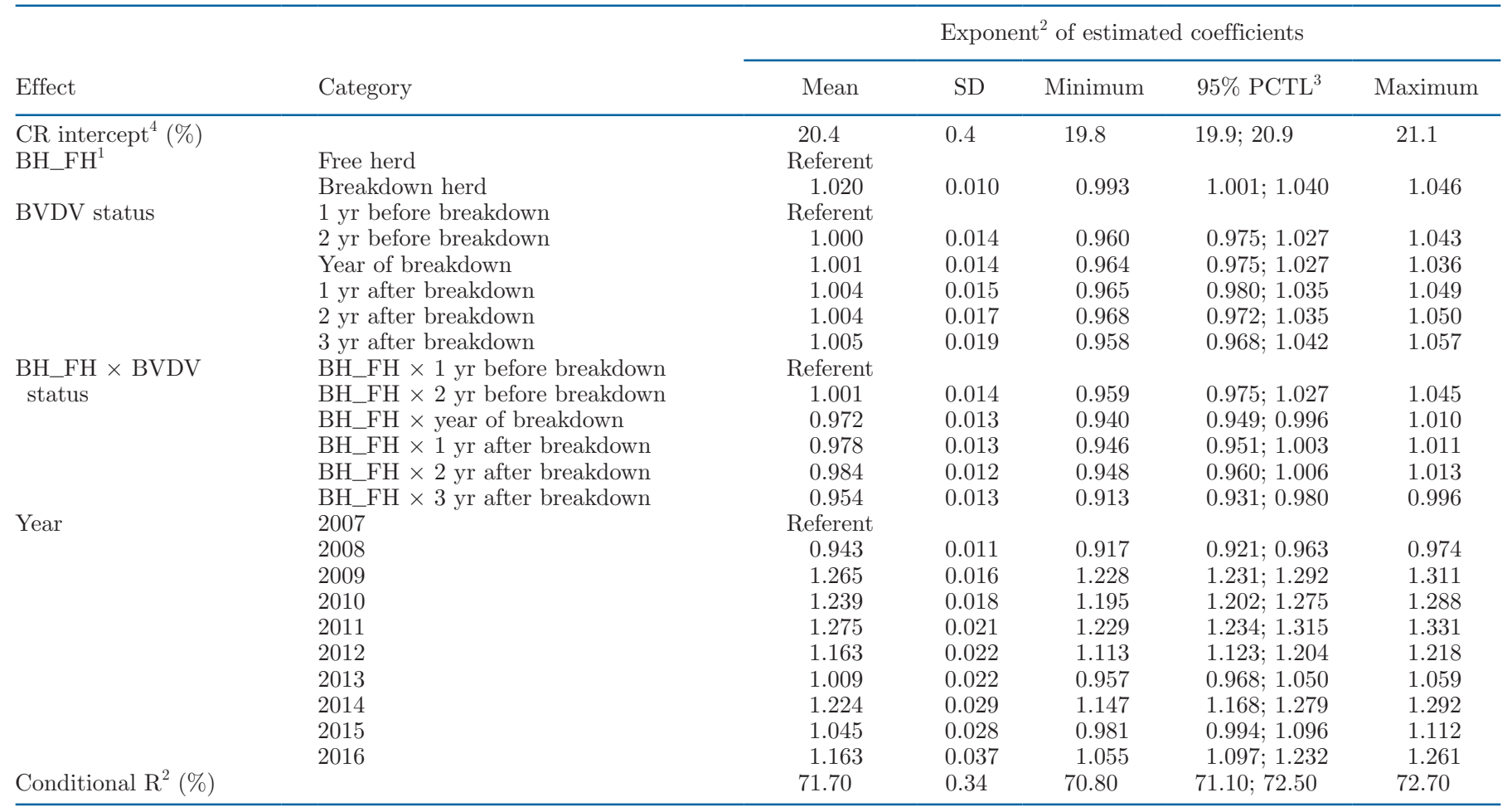

${ }^{1} \mathrm{~A}$ dummy variable indicating herd status [breakdown herd $(\mathrm{BH})$ or free herd $(\mathrm{FH})$ ]. A breakdown herd lost its BVDV-free status during the study period; a free herd remained BVDV free during the whole study period.

${ }^{2}$ The natural exponentiated regression coefficient (except for the intercept term) is the ratio between the mean level of a specific category and the mean level of the reference category.

${ }^{3} 2.5$ th percentile to 97.5 th percentile of the parameter estimate.

${ }^{4}$ The intercept was transformed back to the probability by using the equation $p($ Intercept $)=\frac{\exp \left(\beta_{0}\right)}{1+\exp \left(\beta_{0}\right)}$.

animals more quickly. In addition, a different definition of CMR was used in our study. In the studies by Ersbøll et al. (2003) and Gates et al. (2013), annual rather than quarterly CMR data were used. The annual CMR is higher than the quarterly CMR (Santman-Berends et al., 2014, 2019). We used quarterly CMR data in our analysis to determine the short-term effects of new BVDV introductions.

The effect of a new introduction of BVDV on CIV was only statistically significant $(95 \%$ PCTL $>1$ or $<1)$ for herds that had been BVDV free for at least $3 \mathrm{yr}$, as was shown in the subanalysis. Prior studies had conflicting results. Valle et al. (2001), Berends et al. (2008), and Gates et al. (2013) found no apparent effects; however, other studies observed a longer CIV (ranging from 7 to $9 \mathrm{~d}$ ) as a consequence of BVDV infection (Niskanen et al., 1995; Burgstaller et al., 2016). These different results may be due to the heterogeneity of the studied herds. In our study, herds that had been BVDV free for a longer time period had more susceptible cows. When
BVDV was introduced into these herds, more naive cows could be transiently infected. This may further lead to increased abortion rates, decreased conception rates, increased early embryonic deaths, and so on (Houe et al., 1993; Berends et al., 2008; Burgstaller et al., 2016), resulting in an extended average CIV.

The CR was lower in breakdown herds in the year when BVDV was introduced; this finding is contrary to previous studies which suggested that BVDV infection results in higher risk of culling (Bennett et al., 1999; Valle et al., 2001; Tiwari et al., 2005) or has no significant effect on culling (Niskanen et al., 1995; Gates et al., 2013). A possible explanation may be that in the BVDV-free program, a new infection usually starts with a small number of PI animals that will be quickly detected and culled. Herds that are certified BVDV free have no PI animal (Figure 1). After obtaining the BVDV-free certificate, the herd enters the monitoring phase (phase II) and is monitored by testing 5 randomly selected young stock at the age of 8 to 12 mo with 


\author{
Yue et al.: NEW BOVINE VIRAL DIARRHEA VIRUS INTRODUCTION
}

Table 6. Summarized exponentiated regression coefficients of the generalized linear mixed-effects model (with logit-link function and negative binomial distribution) with 200 iterations for the annual effect of bovine viral diarrhea virus (BVDV) breakdown on calf mortality rate (CMR, $\%$ ) in 327 breakdown herds $^{1}$ and 2,840 free herds ${ }^{1}$ in the Netherlands

\begin{tabular}{|c|c|c|c|c|c|c|c|}
\hline \multirow[b]{2}{*}{ Effect } & \multirow[b]{2}{*}{ Category } & \multicolumn{6}{|c|}{ Exponent $^{2}$ of estimated coefficients } \\
\hline & & Mean & $\mathrm{SD}$ & $95 \% \mathrm{PCTL}^{3}$ & Mean & $\mathrm{SD}$ & 95\% PCTL \\
\hline \multirow{3}{*}{$\begin{array}{l}\text { CMR intercept }{ }^{4}(\%) \\
\text { BH_FH }{ }^{1}\end{array}$} & & 1.34 & 0.06 & $1.22 ; 1.43$ & 1.30 & 0.05 & $1.20 ; 1.38$ \\
\hline & Free herd & Referent & & & Referent & & \\
\hline & Breakdown herd & 1.105 & 0.023 & $1.062 ; 1.150$ & 1.265 & 0.016 & $1.231 ; 1.292$ \\
\hline \multirow{7}{*}{$\begin{array}{l}\text { Herd size } \\
\text { BVDV status }\end{array}$} & 2 yr before breakdown & 1.002 & 0.037 & $0.937 ; 1.081$ & - & - & - \\
\hline & Year of breakdown & 0.993 & 0.033 & $0.924 ; 1.047$ & - & - & - \\
\hline & $1 \mathrm{yr}$ after breakdown & 0.988 & 0.053 & $0.889 ; 1.093$ & - & - & - \\
\hline & 2 yr after breakdown & 0.969 & 0.069 & $0.821 ; 1.089$ & - & - & - \\
\hline & 3 yr after breakdown & 0.961 & 0.083 & $0.796 ; 1.106$ & - & - & - \\
\hline & Q1 after breakdown ${ }^{5}$ & - & - & - & 0.995 & 0.030 & $0.936 ; 1.052$ \\
\hline & Q2 after breakdown ${ }^{5}$ & - & - & - & 1.011 & 0.031 & $0.958 ; 1.072$ \\
\hline \multirow{7}{*}{$\begin{array}{l}\text { BH_FH } \times \text { BVDV } \\
\text { status }\end{array}$} & BH_FH $\times 1$ yr after breakdown & 1.096 & 0.030 & $1.048 ; 1.153$ & - & - & - \\
\hline & BH_FH $\times 2$ yr after breakdown & 1.034 & 0.026 & $0.987 ; 1.087$ & - & - & - \\
\hline & BH_FH $\times 3$ yr after breakdown & 1.067 & 0.031 & $1.001 ; 1.131$ & - & - & - \\
\hline & BH_FH $\times$ Q1 after breakdown & - & - & - & 1.070 & 0.030 & $1.009 ; 1.134$ \\
\hline & BH_FH $\times$ Q2 after breakdown & - & - & - & 0.941 & 0.026 & $0.890 ; 0.991$ \\
\hline & BH_FH $\times$ Q3 after breakdown & - & - & - & 1.108 & 0.033 & $1.048 ; 1.179$ \\
\hline & BH_FH $\times$ Q4 after breakdown & - & - & - & 0.824 & 0.032 & $0.768 ; 0.889$ \\
\hline \multirow[t]{6}{*}{ Year } & 2011 & Referent & & & Referent & & \\
\hline & 2012 & 1.045 & 0.031 & $0.991 ; 1.113$ & 1.071 & 0.022 & $1.027 ; 1.116$ \\
\hline & 2013 & 1.161 & 0.056 & $1.058 ; 1.278$ & 1.192 & 0.037 & $1.137 ; 1.266$ \\
\hline & 2014 & 1.131 & 0.080 & $0.996 ; 1.307$ & 1.130 & 0.046 & $1.041 ; 1.224$ \\
\hline & 2015 & 1.255 & 0.112 & $1.075 ; 1.516$ & 1.224 & 0.066 & $1.099 ; 1.373$ \\
\hline & 2016 & 1.454 & 0.159 & $1.198 ; 1.811$ & - & - & - \\
\hline Season $^{6}$ & Summer & Referent & & & Referent & & \\
\hline
\end{tabular}

${ }^{1}$ A dummy variable indicating herd status [breakdown herd $(\mathrm{BH})$ or free herd $(\mathrm{FH})$ ]. A breakdown herd lost its BVDV-free status during the study period, and a free herd remained BVDV free during the whole study period.

${ }^{2}$ The natural exponentiated regression coefficient (except for the intercept term) is the ratio between the mean level of a specific category and the mean level of the reference category.

${ }^{3} 2.5$ th percentile to 97.5 th percentile of the parameter estimate.

${ }^{4}$ The intercept was transformed back to the probability by using the equation $p($ Intercept $)=\frac{\exp \left(\beta_{0}\right)}{1+\exp \left(\beta_{0}\right)}$.
${ }^{5} \mathrm{Q} 1, \mathrm{Q} 2, \mathrm{Q} 3, \mathrm{Q} 4=$ the first, second, third, and fourth quarter following BVDV breakdown.

${ }^{6}$ Spring (March-May), summer (June-August), autumn (September-November), winter (December to next February).

an antibody ELISA every 6 mo or testing all newborn calves in the herd with an antigen ELISA (Veldhuis et al., 2018; van Duijn et al., 2019). Furthermore, in $49 \%$ of breakdown herds antigen-positive animals are detected, and only $3.87 \%(782 / 20,213)$ were confirmed as PI animals (van Duijn et al., 2019). Therefore, BVDV breakdown is more likely to be due to transient infection. Transiently infected cows will develop antibodies in 2 to 3 wk after infection, which often leads to lifelong seropositivity, and therefore the transiently infected cows do not need to be culled (Houe et al., 2006; Scharnböck et al., 2018). In addition, the few herds that have detected PI calves only need to cull a small number of PI calves. The small number of PI animals has only a limited effect on the annual CR of breakdown herds.

The main reason for the limited effects of a new BVDV introduction on herd performance is the effective control measures of the BVDV-free program. In this study, the specific reasons for the introduction of 


\section{Yue et al.: NEW BOVINE VIRAL DIARRHEA VIRUS INTRODUCTION}

BVDV into each herd could not be determined due to lack of data on this. The route on how BVDV was introduced can however be indirectly inferred through the control measures of the BVDV-free program. In the test and cull phase (phase I) of the BVDV-free program, all cattle in the herd are tested for the virus, and the detected PI animals are culled. The herd can be certified as BVDV free only if the virus is not detected in newborn calves for 10 consecutive months. This process ensures that there are no PI animals in the herd when the herd is certified as BVDV free. After being certified as BVDV free, the herd has to perform antigen ELISA tests on the purchased animals if the animals are purchased from a herd with a lower BVDV status (Veldhuis et al., 2018). This measure prevents PI animals from entering the lactating herd. Furthermore, after the BVDV breakdown, the herd needs to quickly test and confirm whether there are PI animals in the herd, and remove the PI animals (if any) to obtain the BVDV-free certification again. In the study of van Duijn et al. (2019), the average age of detected PI animals was $7 \mathrm{mo}$, and the 99th percentile was 16 mo. Hence, PI animals are already removed before entering the lactating herd, which prevents them from infecting susceptible cows and causing a negative effect on herd performance. Without a BVDV-free program, BVDV introduction may be noticed and detected when clinical signs appear or when herd performance is notably worsened. Clearly, the effects of the new introduction of BVDV may have a greater negative effect on herd performance of dairy herds that do not participate in a control program. The relatively minor effects of BVDV introduction, as found in our study, show the value of BVDV surveillance. Participation in a BVDV surveillance program can be seen as insurance to limit the negative effects of the introduction of BVDV in a free herd. In addition, all studied herds participated in both the CRV data registration and the BVDV-free program. The overall management of such herds may be better compared with herds that did not participate in these programs (expert opinion). Therefore, the effects of a new BVDV introduction may be underestimated in this study.

In this study, the breakdown date was assumed to be the date of BVDV introduction. Most free herds $(3,811 / 4,334)$ monitor their BVDV status with antibody tests twice a year. The exact moment of introduction of BVDV may lie somewhere before the breakdown date. Yue et al. (2021b) developed 4 different scenarios to determine which period is closest to the true period of BVDV spread in the herd. In the default scenario, the BVDV introduction date is assumed to be the same as the BVDV breakdown date, and in the other sce- narios the BVDV introduction date is set at 3, 6 , or 9 mo before BVDV breakdown date. The authors showed that the default scenario most closely resembles the true period of BVDV infection. In the current study, the same scenarios were tested. However, the model results and conclusion in different scenarios were nearly identical; therefore, these results are not presented.

Our statistical model may have potential limitations due to the nature of some variables. Multicollinearity between the explanatory variable BVDV status and Year is a common issue in the annual analysis of both the linear mixed models (SCC and CIV) and generalized linear mixed models (CR and CMR). This is a foreseeable problem because BVDV status is a categorical variable on a yearly basis (e.g., a breakdown herd was BVDV free in the early years and at some point in time changed to breakdown and kept that status afterward). However, due to the indispensability of the BVDV status and Year variables, they are both retained in the final model. Although multicollinearity could reduce the precision of the estimated coefficients, this will only be a problem for the collinear variables. The coefficient of the variable of interest, the interaction item $B H \_F H \times B V D V$ status, will not be affected, and the performance of the collinear variable $B V D V$ status and Year as controls will not be impaired (Allison, 2012). Furthermore, we tested the overdispersion in the CR model. This is a problem that often appears in models with count data, and influences the standard errors of the indices and other parameters (McCullagh and Nelder, 1989; Hougaard et al., 1997) rather than affecting the coefficients. In our study, from each iteration only the coefficients are stored (not the standard errors) and the obtained distribution of coefficients was used to summarize the model results. Therefore, we considered that overdispersion did not affect the final results of the $\mathrm{CR}$ model. In addition, we ran the SCC, CIV, CR, and CMR models with the duration of BVDV free as a categorical variable, but the models did not improve, and therefore results for this analysis were not provided.

\section{CONCLUSIONS}

In the Dutch BVDV-free program, BVDV-free herds had lower SCC, CR, and CMR, and shorter CIV than BVDV breakdown herds. Within breakdown herds, a new BVDV introduction had a negative but on average relatively small effect on herd performance (mainly on SCC and CMR). The modest effect is likely due to the fact that within the BVDV-free program these herds did monitor BVDV and were obliged to detect and cull PI animals. Our results inform that implementing the 
Yue et al.: NEW BOVINE VIRAL DIARRHEA VIRUS INTRODUCTION

BVDV surveillance program is expected to limit the negative effects of BVDV introduction at the herd level substantially.

\section{ACKNOWLEDGMENTS}

This research was funded by the China Scholarship Council (Beijing, China) and the Sino-Dutch Dairy Development Center (Beijing, China). The authors thank CRV (Arnhem, the Netherlands) for providing herd information data, and Anouk M. B. Veldhuis (Royal GD, Deventer, the Netherlands) for her contribution to data acquisition. The authors report no conflict of interest.

\section{REFERENCES}

Allison, P. 2012. When can you safely ignore multicollinearity. Accessed Dec. 1, 2020. https://statisticalhorizons.com/multicollinearity.

Baker, J. C. 1995. The clinical manifestations of bovine viral diarrhea infection. Vet. Clin. North Am. Food Anim. Pract. 11:425-445. https://doi.org/10.1016/S0749-0720(15)30460-6.

Barton, K., and M. K. Barton. 2019. Package 'MuMIn': Multi-Model Inference. Accessed Jun. 9, 2021. https://CRAN.R-project.org/ package $=$ MuMIn

Bates, D., M. Mächler, B. Bolker, and S. Walker. 2015. Fitting linear mixed-effects models using lme4. J. Stat. Softw. 67:1-48. https:// doi.org/10.18637/jss.v067.i01.

Beaudeau, F., C. Fourichon, A. Robert, A. Joly, and H. Seegers. 2005. Bulk milk somatic cell counts and bovine viral diarrhoea virus (BVDV) infection in 7252 dairy herds in Brittany (western France). Prev. Vet. Med. 72:163-167. https://doi.org/10.1016/j .prevetmed.2005.08.017.

Bennett, R., K. Christiansen, and R. Clifton-Hadley. 1999. Modelling the effect of livestock disease on production: Case studies of nonnotifiable diseases of farm animals in Great Britain. Anim. Sci. 68:681-689. https://doi.org/10.1017/S1357729800050700.

Berends, I. M., W. Swart, K. Frankena, J. Muskens, T. Lam, and G. van Schaik. 2008. The effect of becoming BVDV-free on fertility and udder health in Dutch dairy herds. Prev. Vet. Med. 84:48-60. https://doi.org/10.1016/j.prevetmed.2007.11.002.

Burgstaller, J., W. Obritzhauser, S. Kuchling, I. Kopacka, B. Pinior, and J. Kofer. 2016. The effect of bovine viral diarrhoea virus on fertility in dairy cows: Two case-control studies in the province of Styria, Austria. Berl. Munch. Tierarztl. Wochenschr. 129:103-110. https://doi.org/10.2376/0005-9366-129-103.

David, G. P., T. Crawshaw, R. Gunning, R. Hibberd, G. Lloyd, and P. Marsh. 1994. Severe disease in adult dairy cattle in three UK dairy herds associated with BVD virus infection. Vet. Rec. 134:468-472. https://doi.org/10.1136/vr.134.18.468.

Derks, M., T. van Werven, H. Hogeveen, and W. D. Kremer. 2013. Veterinary herd health management programs on dairy farms in the Netherlands: Use, execution, and relations to farmer characteristics. J. Dairy Sci. 96:1623-1637. https://doi.org/10.3168/jds .2012-6106.

Diéguez, F. J., E. Yus, M. J. Vilar, M. L. Sanjuán, and I. Arnaiz. 2009. Effect of the bovine viral diarrhoea virus (BVDV) infection on dairy calf rearing. Res. Vet. Sci. 87:39-40. https://doi.org/10 .1016/j.rvsc.2009.01.002.

Dohoo, I. R., W. Martin, and H. E. Stryhn. 2003. Veterinary Epidemiologic Research. AVC Inc.

Ersbøll, A., H. Rugbjerg, and H. Stryhn. 2003. Increased mortality among calves in Danish cattle herds during bovine virus diarrhoea infection. Acta Vet. Scand. 44(Suppl 1):49. https://doi.org/10 .1186/1751-0147-44-S1-P49.

Evans, C., B. Pinior, M. Larska, D. Graham, M. Schweizer, C. Guidarini, N. Decaro, J. Ridpath, and M. C. Gates. 2019. Global knowl- edge gaps in the prevention and control of bovine viral diarrhoea (BVD) virus. Transbound. Emerg. Dis. 66:640-652. https://doi .org/10.1111/tbed.13068.

Gates, M. C., R. W. Humphry, and G. J. Gunn. 2013. Associations between bovine viral diarrhoea virus (BVDV) seropositivity and performance indicators in beef suckler and dairy herds. Vet. J. 198:631-637. https://doi.org/10.1016/j.tvjl.2013.09.017.

GD Animal Health. 2011. Monitoring animal health cattle. Highlights report third quarter 2011 (in Dutch).

GD Animal Health. 2018. Monitoring animal health cattle. Highlights report first quarter 2018 (in Dutch).

GD Animal Health. 2020. Livestock news cattle September 2020 (in Dutch).

Graham, D. A., T. A. Clegg, M. Lynch, and S. J. More. 2013. Herdlevel factors associated with the presence of bovine viral diarrhoea virus in herds participating in the voluntary phase of the Irish national eradication programme. Prev. Vet. Med. 112:99-108. https: //doi.org/10.1016/j.prevetmed.2013.07.011.

Gunn, G. J., H. W. Saatkamp, R. W. Humphry, and A. W. Stott. 2005. Assessing economic and social pressure for the control of bovine viral diarrhoea virus. Prev. Vet. Med. 72:149-162. https:// doi.org/10.1016/j.prevetmed.2005.08.012.

Hartig, F., and M. F. Hartig. 2017. Package 'DHARMa': Residual Diagnostics for Hierarchical (Multi-Level / Mixed) Regression Models. Accessed Jun. 9, 2021. https://CRAN.R-project.org/package $=$ DHARMa

Heuer, C., A. Healy, and C. Zerbini. 2007. Economic effects of exposure to bovine viral diarrhea virus on dairy herds in New Zealand. J. Dairy Sci. 90:5428-5438. https://doi.org/10.3168/jds.2007-0258.

Houe, H. 1995. Epidemiology of bovine viral diarrhea virus. Vet. Clin. North Am. Food Anim. Pract. 11:521-547. https://doi.org/10 .1016/S0749-0720(15)30465-5.

Houe, H. 2003. Economic effect of BVDV infection in dairies. Biologicals 31:137-143. https://doi.org/10.1016/S1045-1056(03)00030-7.

Houe, H., A. Lindberg, and V. Moennig. 2006. Test strategies in bovine viral diarrhea virus control and eradication campaigns in $\mathrm{Eu}-$ rope. J. Vet. Diagn. Invest. 18:427-436. https://doi.org/10.1177/ 104063870601800501.

Houe, H., and A. Meyling. 1991. Surveillance of cattle herds for bovine virus diarrhoea virus (BVDV)-infection using data on reproduction and calf mortality. Pages 157-164 in Ruminant Pestivirus Infections. Springer. https://doi.org/10.1007/978-3-7091-9153-8_18.

Houe, H., K. M. Pedersen, and A. Meyling. 1993. The effect of bovine virus diarrhoea virus infection on conception rate. Prev. Vet. Med. 15:117-123. https://doi.org/10.1016/0167-5877(93)90107-5.

Hougaard, P., M. L. T. Lee, and G. A. Whitmore. 1997. Analysis of overdispersed count data by mixtures of Poisson variables and Poisson processes. Biometrics 53:1225-1238. https://doi.org/10 $.2307 / 2533492$.

Khodakaram-Tafti, A., and G. Farjanikish. 2017. Persistent bovine viral diarrhea virus (BVDV) infection in cattle herds. Iran J. Vet. Res. 18:154-163.

Laureyns, J., S. Piepers, S. Ribbens, S. Sarrazin, S. De Vliegher, J. M. van Crombrugge, and J. Dewulf. 2013. Association between herd exposure to BVDV-infection and bulk milk somatic cell count of Flemish dairy farms. Prev. Vet. Med. 109:148-151. https://doi .org/10.1016/j.prevetmed.2012.09.013.

Lindberg, A., J. Brownlie, G. J. Gunn, H. Houe, V. Moening, H. W. Saatkamp, T. Sandvik, and P. S. Valle. 2006. The control of bovine viral diarrhoea virus in Europe: Today and in the future. Rev. Sci. Tech. 25:961-979. https://doi.org/10.20506/rst.25.3.1703.

Lindberg, A., and U. Emanuelson. 1997. Effect of bovine viral diarrhea virus infection on average annual milk yield and average bulk milk somatic cell counts in Swedish dairy herds. Epid. Sante Anim. 31-32:10.11.1-10.11.3.

Lüdecke, D., D. Makowski, and P. Waggoner. 2019. Performance: Assessment of regression models performance. Accessed Jun. 9, 2021. https://CRAN.R-project.org/package=performance.

Magnusson, A., H. Skaug, A. Nielsen, C. Berg, K. Kristensen, M. Maechler, K. van Bentham, B. Bolker, M. Brooks, and M. M. Brooks. 2017. Package 'glmmTMB': Generalized Linear Mixed 


\section{Yue et al.: NEW BOVINE VIRAL DIARRHEA VIRUS INTRODUCTION}

Models using Template Model Builder. Accessed Jun. 9, 2032. https://CRAN.R-project.org/package=glmmTMB.

McCullagh, P., and J. A. Nelder. 1989. Over-dispersion. Pages 174-175 in Generalized Linear Models. Chapman and Hall.

Nakagawa, S., and H. Schielzeth. 2013. A general and simple method for obtaining $\mathrm{R}^{2}$ from generalized linear mixed-effects models. Methods Ecol. Evol. 4:133-142. https://doi.org/10.1111/j.2041 $-210 x .2012 .00261 . x$.

Niskanen, R., U. Emanuelson, J. Sundberg, B. Larsson, and S. Alenius. 1995. Effects of infection with bovine virus diarrhoea virus on health and reproductive performance in 213 dairy herds in one county in Sweden. Prev. Vet. Med. 23:229-237. https://doi.org/10 .1016/0167-5877(94)00437-N.

Pinior, B., S. Garcia, J. J. Minviel, and D. Raboisson. 2019. Epidemiological factors and mitigation measures influencing production losses in cattle due to bovine viral diarrhoea virus (BVDV) infection: A meta-analysis. Transbound. Emerg. Dis. 66:2426-2439. https://doi.org/10.1111/tbed.13300.

Pritchard, G. C., E. Borland, L. Wood, and D. Pritchard. 1989. Severe disease in a dairy herd associated with acute infection with bovine virus diarrhoea virus, Leptospira harjo and Coxiella burnetii. Vet. Rec. 124:625-629. https://doi.org/10.1136/vr.124.24.625.

R Core Team. 2018. R: A language and environment for statistical computing. R Foundation for Statistical Computing.

Richter, V., K. Lebl, W. Baumgartner, W. Obritzhauser, A. Käsbohrer, and B. Pinior. 2017. A systematic worldwide review of the direct monetary losses in cattle due to bovine viral diarrhoea virus infection. Vet. J. 220:80-87. https://doi.org/10.1016/j.tvjl.2017.01 .005 .

Rola, J. G., M. Larska, M. Grzeszuk, L. Bocian, A. Kuta, M. P. Polak, and J. Rola. 2014. Bulk tank milk somatic cell counts in dairy herds with different bovine viral diarrhoea virus status in Poland. Prev. Vet. Med. 116:183-187. https://doi.org/10.1016/j.prevetmed 2014.06.007.

Santman-Berends, I. M., M. Buddiger, A. Smolenaars, C. Steuten, C. Roos, A. van Erp, and G. van Schaik. 2014. A multidisciplinary approach to determine factors associated with calf rearing practices and calf mortality in dairy herds. Prev. Vet. Med. 117:375-387. https://doi.org/10.1016/j.prevetmed.2014.07.011.

Santman-Berends, I. M., M. H. Mars, L. van Duijn, K. van den Broek, and G. van Schaik. 2017. A quantitative risk-analysis for introduction of Bovine Viral Diarrhoea Virus in the Netherlands through cattle imports. Prev. Vet. Med. 146:103-113. https://doi.org/10 .1016/j.prevetmed.2017.08.003.

Santman-Berends, I. M., Y. Schukken, and G. van Schaik. 2019. Quantifying calf mortality on dairy farms: Challenges and solutions. J. Dairy Sci. 102:6404-6417. https://doi.org/10.3168/jds.2019-16381.

Scharnböck, B., F.-F. Roch, V. Richter, C. Funke, C. L. Firth, W. Obritzhauser, W. Baumgartner, A. Käsbohrer, and B. Pinior. 2018. A meta-analysis of bovine viral diarrhoea virus (BVDV) prevalences in the global cattle population. Sci. Rep. 8:14420. https://doi.org/ 10.1038/s41598-018-32831-2.

Shafaei Novdeh, J., R. Narenji Sani, H. Staji, A. Jebelli Javan, and H. Hasjemyadeh. 2020. Relationship between bulk tank milk somatic cell count and bovine viral diarrhea status in dairy farms in Semnan. Iran. Vet. J. 16:40-48. https://doi.org/10.22055/ivj.2019 .140053 .2052 .

Stott, A. W., R. W. Humphry, and G. J. Gunn. 2010. Modelling the effects of previous infection and re-infection on the costs of bovine viral diarrhoea outbreaks in beef herds. Vet. J. 185:138-143. https: //doi.org/10.1016/j.tvjl.2009.05.020.

Tiwari, A., J. A. VanLeeuwen, I. R. Dohoo, H. Stryhn, G. P. Keefe, and J. P. Haddad. 2005. Effects of seropositivity for bovine leukemia virus, bovine viral diarrhoea virus, Mycobacterium avium subspecies paratuberculosis, and Neospora caninum on culling in dairy cattle in four Canadian provinces. Vet. Microbiol. 109:147-158. https://doi.org/10.1016/j.vetmic.2005.05.011.

Tschopp, A., R. Deiss, M. Rotzer, S. Wanda, B. Thomann, G. Schüpbach-Regula, and M. Meylan. 2017. A matched case-control study comparing udder health, production and fertility parameters in dairy farms before and after the eradication of Bovine Virus Diarrhoea in Switzerland. Prev. Vet. Med. 144:29-39. https://doi.org/ 10.1016/j.prevetmed.2017.05.016.

Valle, P. S., S. W. Martin, and E. Skjerve. 2001. Time to first calving and calving interval in bovine virus diarrhoea virus (BVDV) seroconverted dairy herds in Norway. Prev. Vet. Med. 51:17-36. https: //doi.org/10.1016/S0167-5877(01)00204-5.

van Duijn, L., A. M. B. Veldhuis, M. H. Mars, B. de Roo, and T. Lam. 2019. Efficacy of a voluntary BVDV control programme: Experiences from the Netherlands. Vet. J. 245:55-60. https://doi.org/10 $.1016 /$ j.tvjl.2018.12.016.

van Roon, A., M. Mercat, G. van Schaik, M. Nielen, D. Graham, S. More, M. Guelbenzu-Gonzalo, C. Fourichon, A. Madouasse, and I. Santman-Berends. 2020. Quantification of risk factors for bovine viral diarrhea virus in cattle herds: A systematic search and meta-analysis of observational studies. J. Dairy Sci. 103:9446-9463. https://doi.org/10.3168/jds.2020-18193.

Veldhuis, A. M. B., M. H. Mars, L. van Duijn, P. Wever, and G. van Schaik. 2018. Risk factor analysis on introduction of BVDV into previously BVDV-free herds in the Netherlands. Pages 221-230 in Proc. Society for Veterinary Epidemiology and Preventive Medicine (SVEPM).

Vonk Noordegraaf, A., J. A. A. M. Buijtels, A. A. Dijkhuizen, P. Franken, J. A. Stegeman, and J. Verhoeff. 1998. An epidemiological and economic simulation model to evaluate the spread and control of infectious bovine rhinotracheitis in the Netherlands. Prev. Vet Med. 36:219-238. https://doi.org/10.1016/S0167-5877(98)00081 -6 .

Waage, S., J. Krogsrud, and O. Nyberg. 1994. The Norwegian programme for eradication of bovine viral diarrhoea/mucosal disease. Pages 773-776 in the 18th World Buiatrics Congress: 26th Congress of the Italian Association of Buiatrics. Societa Italiana di Buiatria.

Yue, X., W. Steeneveld, M. van der Voort, G. van Schaik, J. C. M. Vernooij, C. van Duijn, and H. Hogeveen. 2021a. Data underlying the manuscript: The effect of new bovine viral diarrhea virus (BVDV) introduction on somatic cell count, calving interval, culling rate and calf mortality of dairy herds in the Dutch BVDV-free program. DANS. https://doi.org/10.17026/dans-2zc-7w88.

Yue, X., W. Steeneveld, M. van der Voort, G. van Schaik, J. C. M. Vernooij, L. van Duijn, A. M. B. Veldhuis, and H. Hogeveen. 2021b. The impact of bovine viral diarrhea virus introduction on milk production of Dutch dairy herds. J. Dairy Sci. 104:2074-2086. https://doi.org/10.3168/jds.2020-18866.

ZuivelNL. 2020. Combating IBR \& BVD: Protocols. Accessed Sep. 5, 2020. https://www.zuivelnl.org/programmas/ibr-en-bvd/ bestrijding-ibr-bvd-protocollen.

\section{ORCIDS}

Xiaomei Yue ๑ https://orcid.org/0000-0003-4198-2541 Mariska van der Voort (ㄴ) https://orcid.org/0000-0003-0503-259X

Wilma Steeneveld (ㄱ https://orcid.org/0000-0002-8329-0466

Gerdien van Schaik @ https://orcid.org/0000-0002-0460-2629

Johannes C. M. Vernooij (i) https://orcid.org/0000-0002-2646-9216

Linda van Duijn ( https://orcid.org/0000-0003-3799-4777

Henk Hogeveen ๑ https://orcid.org/0000-0002-9443-1412 